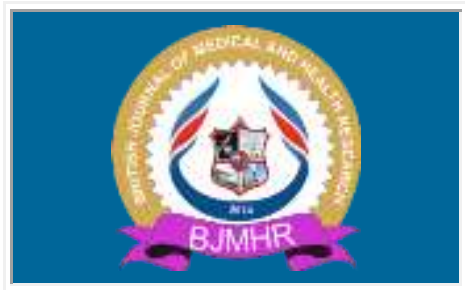

\title{
BJMHR
}

British Journal of Medical and Health Research Journal home page: www.bjmhr.com

\section{Anaplastic Carcinoma In A Young Female: An Incidental} Finding In A Colloid Goitre

\author{
Shagufta Shahin ${ }^{1}$, Anjum Ara ${ }^{2}$, Sadaf Haiyat ${ }^{1}$ Kafil Akhtar $^{1 *}$ \\ 1.Department of Pathology, Jawaharlal Nehru Medical College, Aligarh Muslim \\ University, Aligarh, \\ 2.Faculty of Dentistry, Jamia Milia Islamia, New Delhi, India.
}

\begin{abstract}
Anaplastic carcinomas are the lethal thyroid neoplasms and have poor survival rate and prognosis. Pre existing well differentiated thyroid neoplasms can give rise to anaplastic carcinoma. Here, we report a case of anaplastic carcinoma in a young female in a colloid goitre as an incidental finding diagnosed by histopathological examination. Thyroid function tests showed suppressed TSH and elevated FT4 and FT3. Anti-thyroid hormone drugs were started. Thyrotropin receptor antibody was negative. USG neck showed single hypoechoic lesion in the periphery of the right lobe. A thyroid scan revealed focal hot and cold nodules and fine needle aspiration biopsy (FNAB) of the thyroid gland showed colloid nodule. Patient underwent right side lobectomy and final histopathology showed anaplastic thyroid carcinoma. Our case is interesting from a pathophysiologic perspective, since it suggests that nodular goiter can be associated with an aggressive form of thyroid carcinoma. We would like to emphasize that there should be a high index of suspicion in patients with nodular goiter for careful evaluation to detect any associated cancer.
\end{abstract}

Keywords: Anaplastic carcinoma, Colloid goitre, Incidental, Thyroid 


\section{INTRODUCTION}

Amongst the thyroid carcinomas, anaplastic carcinomas are the most aggressive and the rare tumours. They account for less than $2 \%$ of all thyroid neoplasms. ${ }^{1}$ They usually arise from pre existing well differentiated thyroid carcinoma or de novo.

The incidence of malignancy is $9.0 \%$ in the toxic and $10.58 \%$ in the non-toxic multinodular goiter group. ${ }^{1}$ In a review of resected multinodular goiters by Pedamallu, papillary carcinoma was found to be the most common cancer in $(7 \%) .^{2}$ However, the finding of anaplastic carcinoma is still very rare. This disease progresses rapidly and treatment should be promptly initiated. Only combined multimodal therapy can impact favorably on the local control rate to prevent the high mortality rate from asphyxiation.

Anaplastic cells do not express thyroid specific genes and thyroid function test are usually normal. ${ }^{2}$ Alwani and Rathod explained that hyperthyroidism with thyroid carcinoma include those which produce thyroid hormone autonomously, and causes destructive thyrotoxicosis by rapid cancerous invasion of the normal thyroid tissue. ${ }^{2,3}$ Here, we report a case of anaplastic carcinoma in a young female in a colloid goitre as an incidental finding.

\section{CASE REPORT}

A 33 year old female presented with a midline neck swelling for four months and a complaint of pain in the swelling for 15 days. There was no history of sudden increase in size, fever, dyspnoea, dysphagia and hoarseness of voice. On examination, patient had a midline neck swelling measuring 5x 3.5 centimetre, which was firm, tender and moving freely with deglutition.

Thyroid profile was advised and TSH measured $0.15 \mu \mathrm{IU} / \mathrm{L}$, free serum thyroxine $\left(\mathrm{T}_{4}\right)$ was $1.56 \mathrm{ng} / \mathrm{dL}$ and free serum triiodothyronine $\left(\mathrm{T}_{3}\right)$ measured $2.4 \mathrm{pg} / \mathrm{mL}$. These levels were suggestive of hyperthyroid state. Rest haematological investigations were normal. Chest X ray was unremarkable. USG neck showed single hypoechoic lesion in the periphery of the right lobe.

Fine Needle Aspiration Cytology (FNAC) was done and brown colour material was aspirated. FNAC smear showed atrophic and reactive follicular epithelial cells along with multiple cystic macrophages. Few atypical cells having nuclear pleomorphism, hyperchromasia were noted. Further, patient underwent for right side lobectomy and specimen was sent for histopathological examination. On gross examination, a single greyish brown, firm, encapsulated globular tissue of $7.2 \times 5.3 \times 2.4 \mathrm{~cm}$ size, with unremarkable outer surface was seen. Cut section showed a single well-defined whitish area in the periphery and rest of the area was gelatinous brown. 
Microscopic examination revealed the features of colloid goitre except the section from the whitish area which showed few clusters as well as singly scattered atypical cells. These atypical cells were large round to spindle in shape, hyperchromatic, pleomorphic with irregular nuclear membrane, coarse chromatin, few have prominent nucleoli and moderate amount of cytoplasm. Occasional multinucleated giant cells were also seen. Areas of necrosis and haemorrhage were noted along with high mitotic count (Figure 1 and 2). Immunohistochemical expression of Vimentin showed diffuse cytoplasmic positivity(Figure 3).. All these features were suggestive of anaplastic carcinoma. Further patient was referred to radiotherapy department for chemotherapy. Six doses of $50 \mathrm{mg} / \mathrm{m}^{2}$ Cisplatin was given at an interval of 21 to 28 days. After six months of chemotherapy, our patient is doing well with no evidence of disease recurrence.

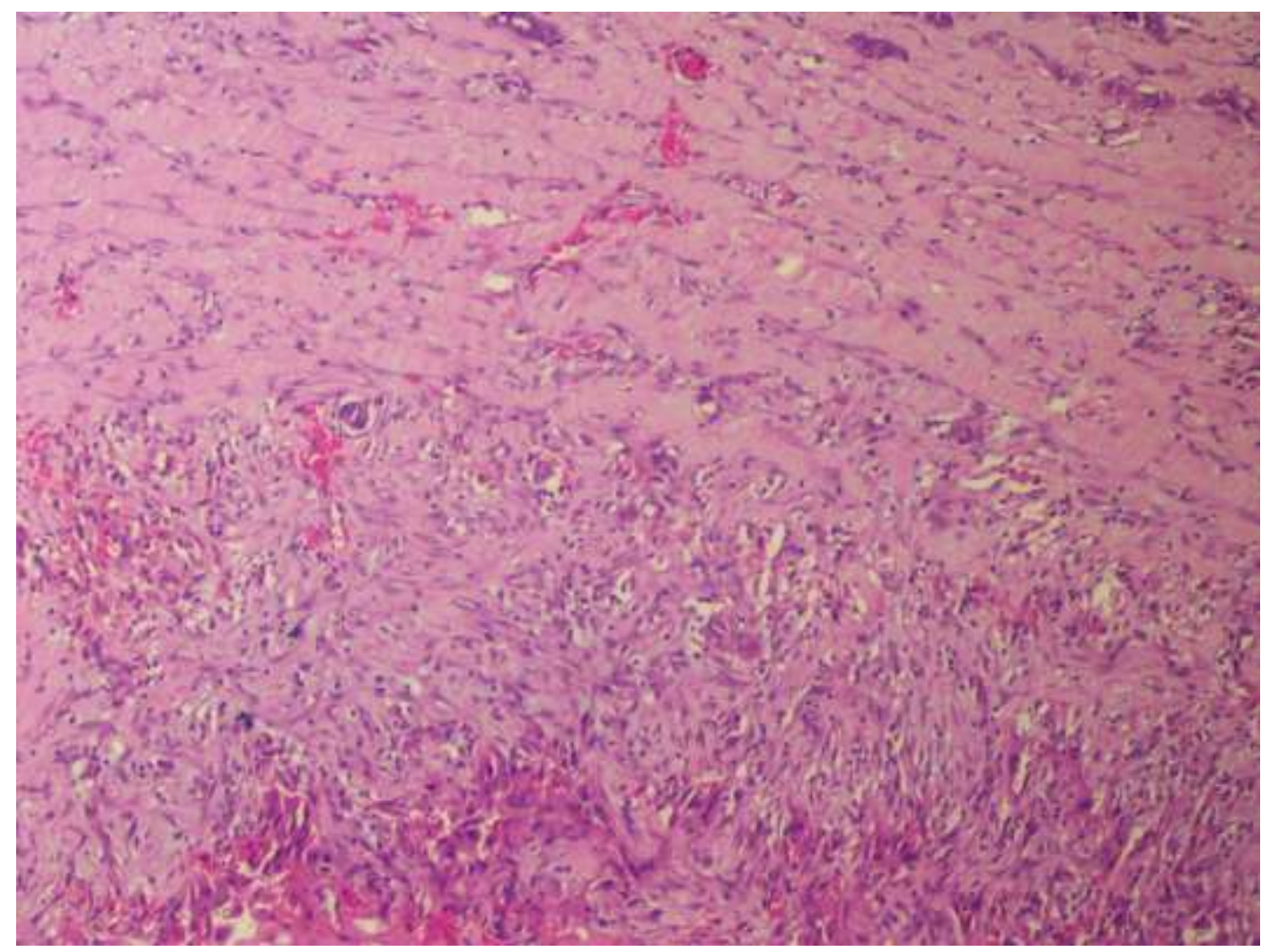

Figure 1: Photomicrograph shows clusters as well as singly scattered atypical cells, large round to spindle in shape with hyperchromatic nuclei and irregular nuclear membrane. Few cells show prominent nucleoli and moderate eosinophilic cytoplasm. Occasional large tumor cells are also seen with areas of necrosis and haemorrhage and high mitotic count. Haematoxylin and Eosin $x$ 10X. 


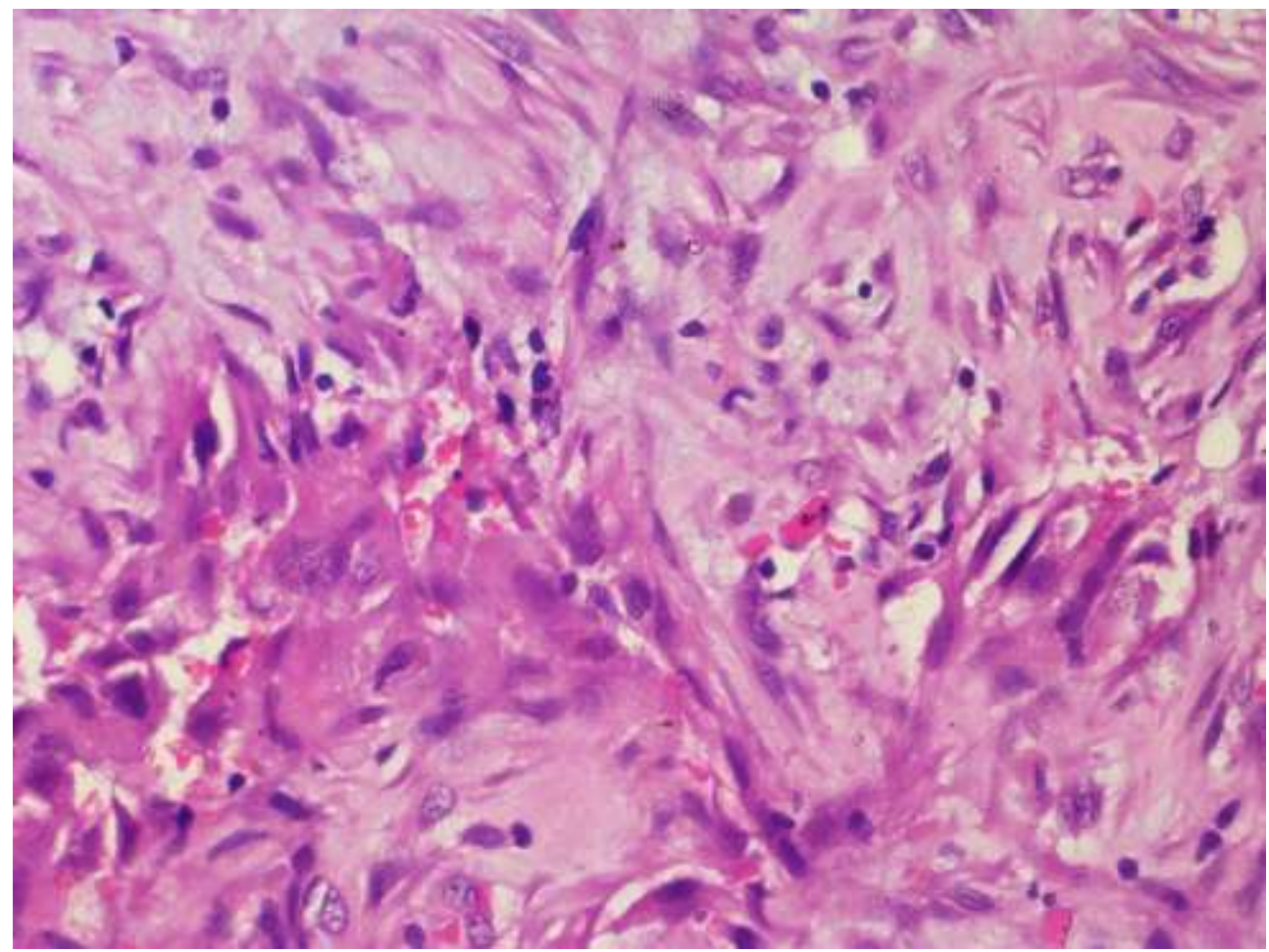

Figure 2: High power of Figure 1.

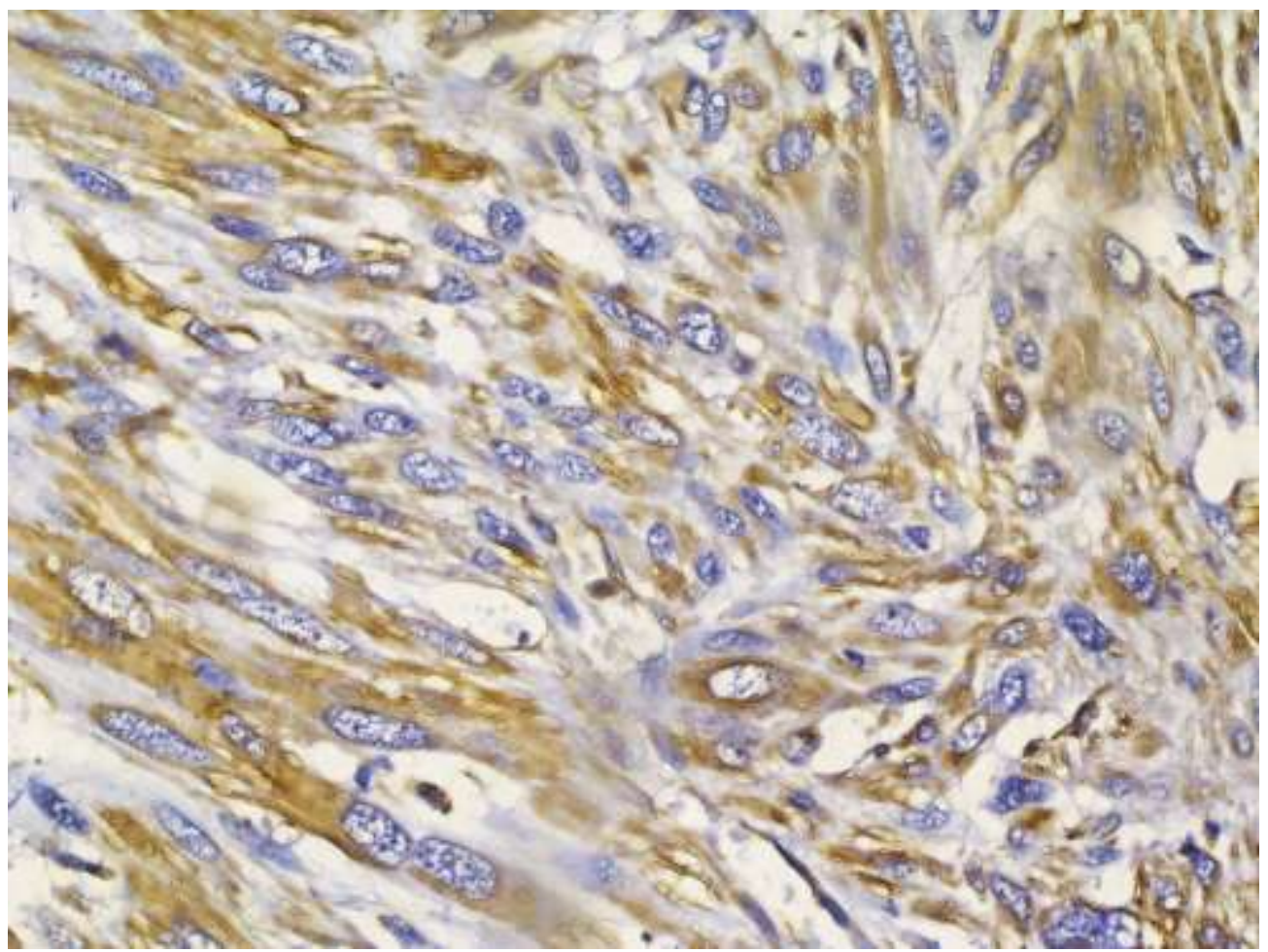

Figure 3: Immunoexpression of Vimentin showed diffuse cytoplasmic positivity in the anaplastic tumor cells. IHC Vimentin $\mathrm{x40X}$.

\section{DISCUSSION}

Anaplastic carcinoma is the most aggressive thyroid neoplasm and generally has a fatal outcome. ${ }^{2}$ They usually have female preponderance and commonly seen in older age group, 60 to 70 years. ${ }^{3}$ Risk factors for anaplastic carcinoma includes pre-existing well differentiated thyroid carcinoma, previous radiation exposure, iodine deficiency, long standing multinodular 
goitre. ${ }^{3}$ They are more frequently seen in endemic goitres areas. ${ }^{4}$ Rapidly growing neck mass is the most common clinical presentation. Other symptoms included pain, dysphagia, hoarseness of voice and dyspnoea. ${ }^{5}$ Distant metastasis at the time of diagnosis can give rise to systemic symptoms. It has been reported that $50 \%$ of cases presented with the distant metastasis at the time of diagnosis, most commonly in lung followed by bone. ${ }^{6,7}$

In our case, patient was young female and has a history of midline neck swelling for 4 months and a complaint of pain from the last 15 days. There were no complaints of rapidly increase in size of swelling, dysphagia, or hoarseness of voice. All the haematological investigations were normal except serum TSH level was slightly decreased and serum T4 was raised. Initially, it was diagnosed as a case of colloid goitre, but after histopathological examination, it was diagnosed as an incidental anaplastic carcinoma.

The incidence of incidental thyroid carcinomas ranges from 6-10\%. ${ }^{8-10}$ Papillary microcarcinomas are the mostly commonly diagnosed incidental tumours and anaplastic carcinomas are rare incidental finding. ${ }^{10,11}$ Gunes et al has reported the case of incidental anaplastic carcinoma in a subtotal thyroidectomy specimen of a 50 year old female, diagnosed as benign colloid nodule by FNAC. She was administered radiotherapy and adjuvant chemotherapy and survived for 1.5 years after treatment. ${ }^{12}$ In contrast, our patient was 33 year old and underwent right lobectomy followed by 6 doses of $50 \mathrm{mg} / \mathrm{m}^{2}$ Cisplatin. After 6 months of chemotherapy, there was no evidence of the disease and our patient is doing well.

\section{CONCLUSION}

Incidence of anaplastic thyroid carcinoma in colloid goitre is almost negligible. However, if they occur, they tend to be fatal. Multiple site aspirations from enlarged thyroid swelling can improve diagnostic accuracy. It is essential to diagnose them at an early stage to aid proper treatment and improve patient's survival.

\section{REFERENCES}

1. Ragazzi M, Ciarrocchi A, Sancisi V, Gandolfi G, Bisagni A, Piana S. Update on anaplastic thyroid carcinoma: Morphological, molecular, and genetic features of the most aggressive thyroid cancer. Int J Endocrinol 2014; 20(14):790-834.

2. Pedamallu R, Pedamallu SB, Rama Rao KV, Pedamallu C. Incidence of occult carcinoma in multinodular goiter using histopathological findings. Int J Surg 2008; 17(1):1-2.

3. Alwani M and Rathod GB. Diagnosis of anaplastic thyroid carcinoma on fine needle aspiration cytology- A rare case report. IAIM. 2015; 2(3):183-187.

4. Nagare MR, Joshi SR, Karwande AV, Pathak SS, Tekwani DT, Jaison J. Anaplastic thyroid carcinoma: a rare case. Ann Applied Bio-Sci 2015; 211(2):6-9. 
5. Sugino K, Ito K, Mimura T, Nagahama M, Fukunari N, Kubo A et al. The important role of operations in the management of anaplastic thyroid carcinoma. Surg 2002;131:245-248.

6. McIver B, Hay ID, Giuffrida DF, Dvorak CE, Grant CS, Thompson GB et al. Anaplastic Thyroid Carcinoma: 50 year experience at a single institution. Surg 2001;130:1028-1034.

7. Silver RJ and Parangi S. Management of thyroid incidentalomas. Surg Clin North Am 2004; 84:907-999.

8. Nagaiah C, Hossain A, Mooney CJ, Parmentier J, Remick SC. Anaplastic thyroid cancer: a review of epidemiology, pathogenesis and treatment. J Oncol 2011; 2011:113.

9. Colak T, Akca T, Kanik A, Yapici D, Aydin S. Total versus sub-total thyroidectomy for the management of benign multinodular goitre in endemic region. ANZ J Surg 2004;74:974-978.

10. Mishra A, Agarwal A, Agarwal G, Mishra SK. Total thyroidectomy for benign thyroid disorders in an endemic region.World J Surg 2001; 25:307-310.

11. Giles Y, Boztepe H, Terzioglu T, Tezelman S. The advantageof total thyroidectomy to avoid re-operation for incidental thyroid cancers in multinodular goitre. Arch Surg 2004; 139: 179-182.

12. Guneş P, Aker FV, Erkan M, Demirtürk P, Dulundu E. Incidental anaplastic thyroid carcinoma: A case report. Turk J Pathol 2008; 24(1):54-58.

\section{BJMHR is \\ - Peer reviewed \\ - Monthly \\ - Rapid publication \\ - Submit your next manuscript at editor@bjmhr.com

